\section{Air and Root-zone Temperatures Influence Growth and Flowering of Snapdragons}

\author{
Khin San Wai ${ }^{1}$ and Steven E. Newman ${ }^{2}$ \\ Department of Horticulture, Mississippi Agricultural and Forestry \\ Experiment Station, P.O. Drawer T, Mississippi State, MS 39762-5519
}

Additional index words. Antirrhinum majus, chilling injury

Abstract. Growth chamber studies using elevated root-zone temperatures and greenhouse studies using two root-zone and two night air temperatures were conducted to determine the effects on growth and flowering of two response groups ['Rainier White' (Group II) and 'Tampico' (Group III)] of cut-flower snapdragons (Antirrhinum majus L.). Chamber-grown snapdragons with the root zone at $30 \mathrm{C}$ had shorter stems and a lower dry weight than those at $20 \mathrm{C}$. Holding the root zone above $26 \mathrm{C}$ increased time to flower. Greenhouse-grown 'Tampico' and 'Rainier White' snapdragon stems were longer with increased root-zone temperature regardless of night air temperature. Time to flower was reduced an average of 6 days with increased root-zone temperature and 12 days when the night air was maintained at $20 \mathrm{C}$. This study demonstrated that the effects of relatively low greenhouse temperatures may be offset by root-zone heat.

Snapdragons are sensitive to cool root-zone temperatures (RZT) and often wilt under high transpiration demands (Rogers, 1992). Cultivars of greenhouse forcing snapdragons have been classified into four genetically distinct groups based on their response to daylength and greenhouse temperature (Rogers, 1992). Group I and II cultivars are adapted to winter greenhouse conditions and short days; Group II requires more time to flower than Group I; Group III is adapted to spring and early summer greenhouse conditions, requiring longer days; and Group IV flowers only at night temperatures >15.5C (Rogers, 1992). Low greenhouse temperatures during winter and early spring months can be tolerated by snapdragons with increased RZT (Roberts et al., 1985; Shedlosky and White, 1987). The objectives of our study were to determine the response of two cut-flower snapdragon cultivars, representing two response groups, to elevated RZT at two night air temperatures.

'Rainier White' and 'Tampico' snapdragons (Ball Seed Co., West Chicago, Ill.) were used. 'Rainier White' is in Group II, suited to winter greenhouse conditions; whereas 'Tampico' is in Group III, suited to spring or summer greenhouse conditions (Ball, 1991). Seeds were sown in 1 sphagnum peat

Received for publication 25 Oct. 1991. Accepted for publication 4 Mar. 1992. Mississippi Agricultural and Forestry Experiment Station Journal Series J-7723. This research was supported in part from a grant from the Horticultural Research Institute. Plant materials were provided by Ball Seed Co., Chicago. The cost of publishing this paper was defrayed in part by the payment of page charges. Under postal regulations, this paper therefore must be hereby marked advertisement solely to indicate this fact.

'Graduate Student. Current address: Horticulture Division, Agricultural Research Institute, Yeagin, Pyinmana, Burma (Myanmar).

${ }^{2}$ Associate Professor, to whom reprint requests should be addressed. South Industries, Laurel, Miss.) was main-

ermiculite medium (v/v) and gern during daylight hours); seedlings were planted after they were 6 to $7 \mathrm{~cm}$ tall $(\approx 21$ days). scale). tained at $20 \pm 1 \mathrm{C}$, with RZTs ranging from 20 to 30C. The RZTs were obtained by passing hot or cold water through opposing pairs of $2.5 \times 2.5-\mathrm{cm}$ aluminum tubing attached to the bottom edges of a $1 \times 1-\mathrm{m}$ aluminum plate with thermally conductive cement. This procedure resulted in a linear temperature gradient between the hot and cold sides (Larsen, 1965). Seedlings were transplanted into thirty-six $5 \times 15-\mathrm{cm}$ polyvinylchloride tubes filled with pasteurized sand placed in six rows on top of the aluminum plate and surrounded with Styrofoam. The rows were parallel to the hot and cold sides and each row represented a RZT treatment: 20, 22, 24, 26, 28 , or 30 C. Six plants (three plants of each cultivar) were used in each row. Nutrient solution (Hoagland and Arnon, 1950) and distilled water were alternately applied by hand as needed. Light was provided 16 $\mathrm{h} \cdot \mathrm{day}^{-1}$ with six 40-W fluorescent cool-white bulbs and six 40-W incandescent bulbs, which provided a quantum flux of 190 $\mu \mathrm{mol} \cdot \mathrm{m}^{-2} \cdot \mathrm{s}^{-1}$.

A double polyethylene-covered greenhouse $(10 \times 30 \mathrm{~m})$ was divided into six individual rooms $(5 \times 10 \mathrm{~m})$ (Fig. 1). Each room had independent night temperature (NT) control. The four interior rooms used in this study were maintained at 13 or $20 \pm 1 \mathrm{C}$ at night. The day temperature (recorded midafternoon) for all units was $26 \pm 5 \mathrm{C}$. Photoperiod was increased by a 4-h night

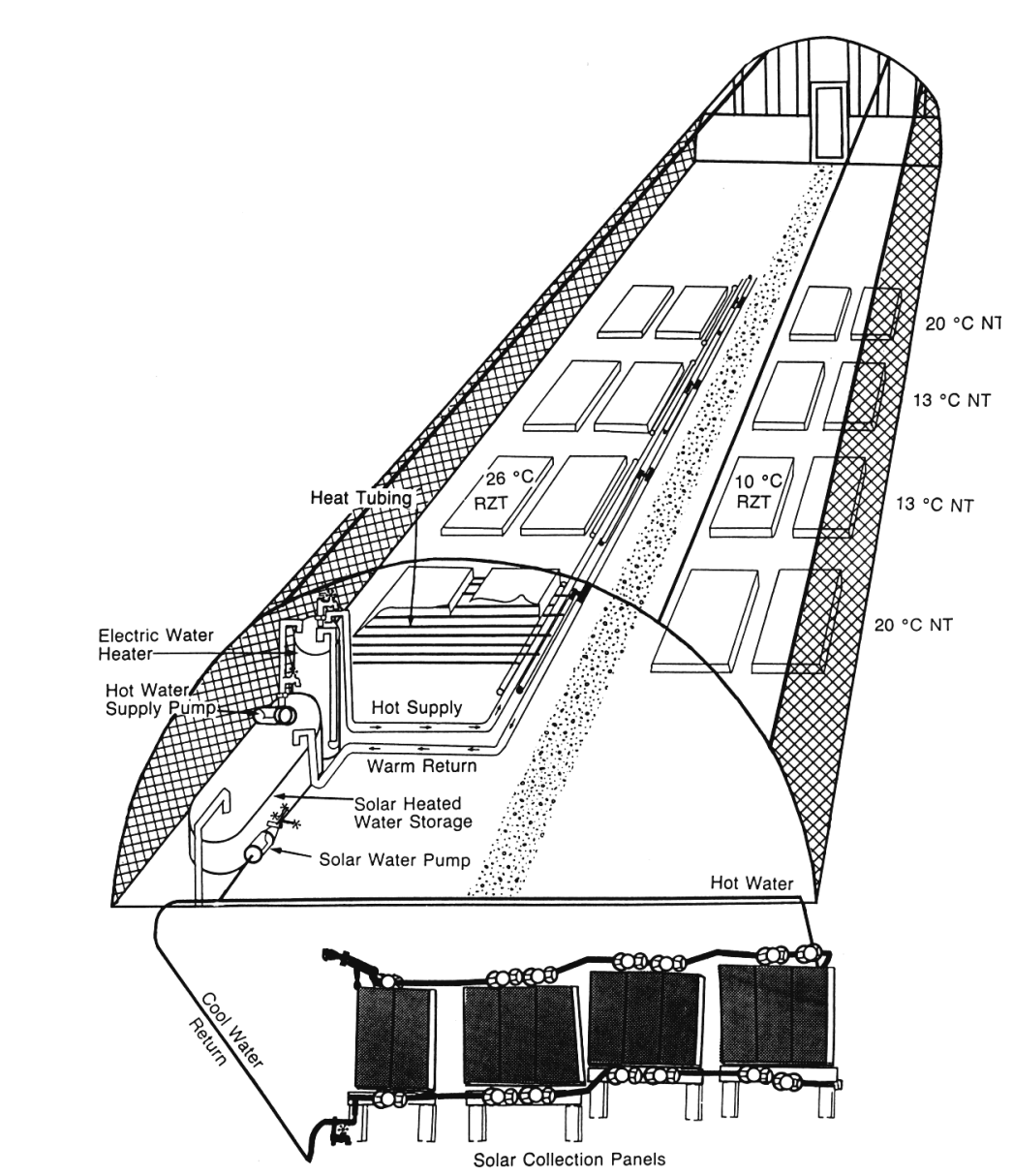

Fig. 1. Diagram of greenhouse layout and solar-generated root-zone heating system (not drawn to 

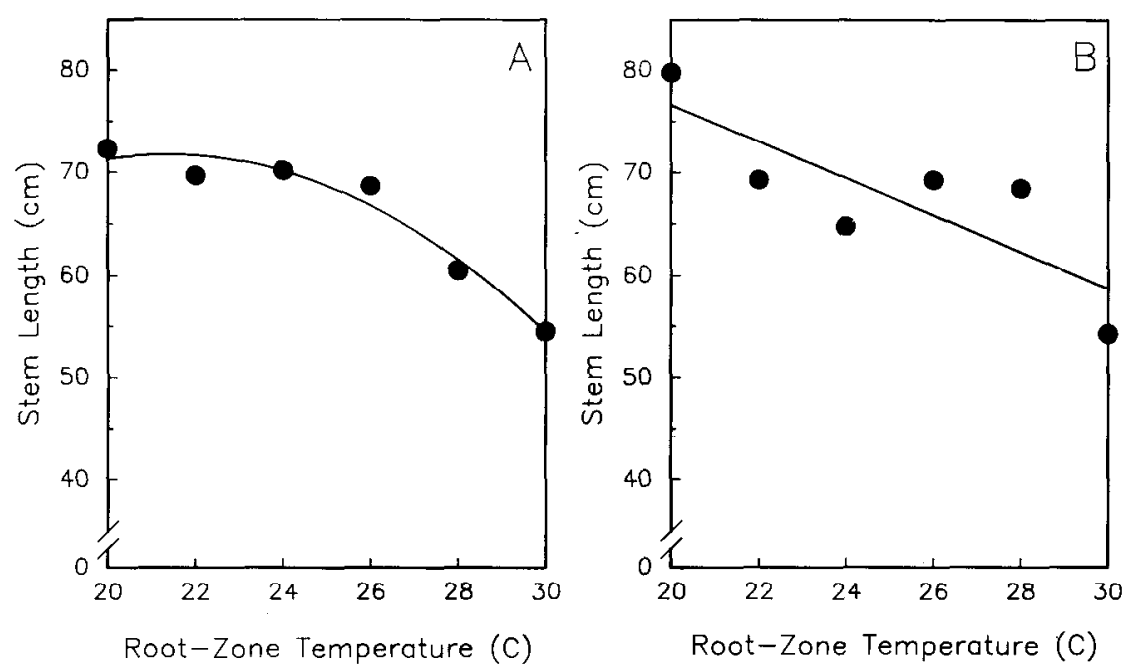

Fig. 2. Regression analyses of root-zone temperature on plant height of growth chamber-grown snapdragons 8 weeks after transplanting (A) 'Rainier White' $\left(y=68.7-8.44 x-5.73 x^{2}, R^{2}=0.76\right)$ and (B) 'Tampico' $\left(\mathrm{y}=79.6-3.13 \mathrm{x}, R^{2}=0.32\right)$. Data presented are means of three observations.
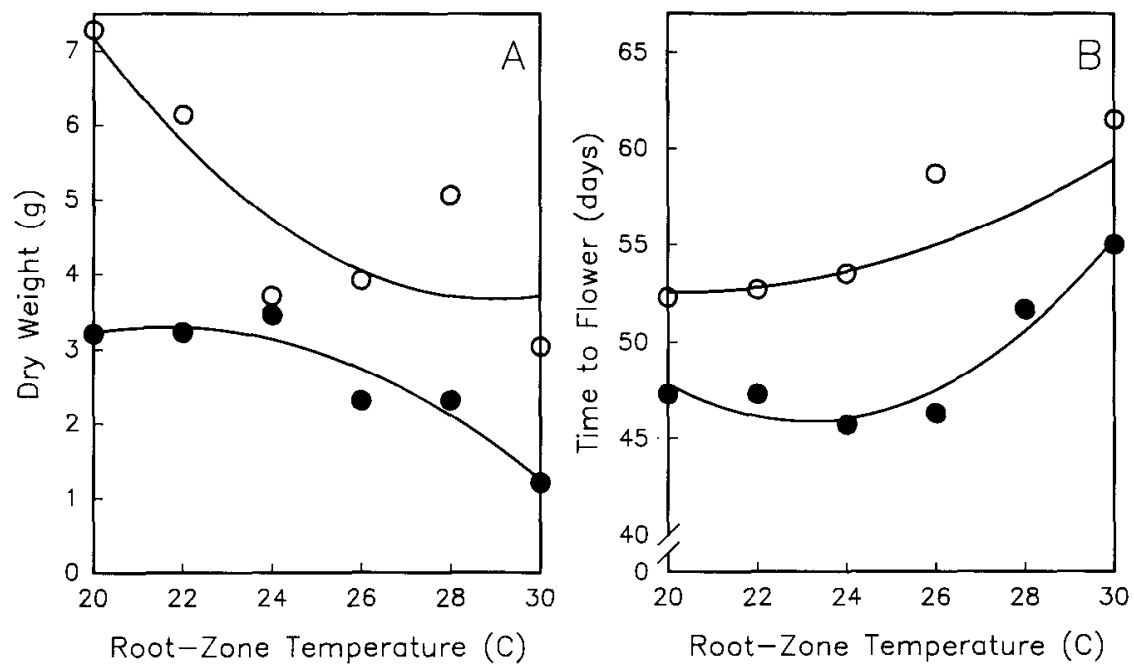

Fig. 3. Regression analyses of root-zone temperature on dry weight and time to flower of growth chamber-grown snapdragons harvested after the lower third of the florets was at anthesis. (A) Dry weight: (๑) 'Rainier White' $\left(y=-10.3+1.26 x-0.03 x^{2}, R^{2}=0.91\right)$; (0) 'Tampico' $(y=$ $40.6-2.55 \mathrm{x}+0.04 \mathrm{x}^{2}, R^{2}=0.73$ ). (B) Time to flower: (๑) 'Rainier White' $(\mathrm{y}=152-9.19 \mathrm{x}$ $+0.20 \mathrm{x}^{2}, R^{2}=0.93$; (O) 'Tampico' $\left(\mathrm{y}=81.1-2.84 \mathrm{x}+0.07 \mathrm{x}^{2}, R^{2}=0.44\right)$. Data presented are means of three observations.

Table 1. Effect of root-zone and night temperature on stem length, dry weight, and time to flower for two flowering groups of cut flower snapdragons ('Rainier and White' and 'Tampico').

\begin{tabular}{lcccccc}
\hline \hline \multirow{2}{*}{ Cultivar } & \multicolumn{2}{c}{ Temp $\left({ }^{\circ} \mathrm{C}\right)$} & & $\begin{array}{c}\text { Stem } \\
\text { length } \\
(\mathrm{cm})\end{array}$ & $\begin{array}{c}\text { Dry wt } \\
\text { (g) }\end{array}$ & $\begin{array}{c}\text { Time } \\
\text { to flower } \\
\text { (days) }\end{array}$ \\
\cline { 2 - 7 } Rainier White & 10 & 13 & $49.4^{2}$ & 7.1 & 66 \\
& 26 & 13 & 59.8 & 7.7 & 62 \\
& 10 & 20 & 64.3 & 5.7 & 55 \\
Tampico & 26 & 20 & 61.7 & 5.1 & 50 \\
& 10 & 13 & 36.5 & 22.4 & 79 \\
& 26 & 13 & 52.0 & 23.9 & 73 \\
& 10 & 20 & 52.5 & 13.0 & 67 \\
& 26 & 20 & 69.1 & 9.5 & 58 \\
& LSD $_{0.05}$ & & 2.7 & 2.3 & 2 \\
\hline
\end{tabular}

${ }^{2}$ Data presented are means of 56 observations.

interruption with incandescent light to counter any differences between snapdragon groups. Two RZT regimes, heated $(26 \pm 1 \mathrm{C})$ and not heated $(10 \pm 1 C)$, were used in each of the four interior units; RZTs reported are based on daily observations, midafternoon, at $10 \mathrm{~cm}$ deep from random locations. Rootzone heating was applied by pumping hot water through 6-mm, flexible, heat-resistant tubing placed directly under the medium. RZT was controlled by a zone valve connected to a thermostat with a remote sensor placed in the medium. The hot-water source was a combination of $11(212 \times 89 \mathrm{~cm})$ solar collector panels with a 212-liter electric water heater (Fig. 1). The nonheated RZT (10C) was achieved by placing the medium in direct contact with the greenhouse floor with no temperature control.

Seedlings grown as previously described were transplanted into a 2 pine bark : 1 sphagnum peat : 1 vermiculite (by volume) medium enclosed by $210 \times 75 \times 15-\mathrm{cm}$ wooden frames $(2.5 \times 14-\mathrm{cm}$ lumber $)$. Four frames were placed into each of four rooms. Plants of both cultivars were transplanted into each frame and spaced $25 \times 19 \mathrm{~cm}$ or 28 plants per frame. The medium was topdressed with $1.8 \mathrm{~kg} \cdot \mathrm{m}^{-}{ }^{3}$ of $14 \mathrm{~N}-6.1 \mathrm{P}-12 \mathrm{~K}$ slow-release fertilizer (Osmocote; Grace/ Sierra Co., Fogelsville, Pa.). Plants were watered manually every other day and fertilized weekly with $300 \mathrm{mg}$ N/liter from $15 \mathrm{~N}$ 7P-14K (Grace/Sierra Co.). Stem length was measured from the medium level to the top of the shoot. Plants were harvested when the florets on the lower third of the raceme were at anthesis; their dry weight was determined after $48 \mathrm{~h}$ at $60 \mathrm{C}$.

Chamber-grown 'Rainier White' snapdragon stems were about equally long at RZTs from 22 to $26 \mathrm{C}$, they were shorter at 28 and 30C (Fig. 2A). Dry weight was highest at 20C (Fig. 3A). 'Rainier White' is a Group II cultivar adapted to winter greenhouse conditions (Rogers, 1992). Time to flowering for 'Rainier White' tended to increase with RZTs above 26C (Fig. 3B).

Stem length of 'Tampico' decreased with increasing RZT (Fig. 2B). Dry weight of 'Tampico' was also reduced, and time to flower was increased at the higher RZTs (Fig. 3 A and B). 'Tampico', a Group III cultivar adapted to spring and summer greenhouse conditions (Rogers, 1992), was detrimentally affected by the high RZTs used in this study; however, 'Rose Pink', another Group III cultivar, was reported to have an optimal RZT of 22C (Wai, 1990).

Greenhouse-grown 'Rainier White' and 'Tampico' responded differently to RZT and NT. 'Ranier White', as would be expected of a Group II cultivar, was better adapted to the cooler greenhouse environment than 'Tampico', as indicated by longer stems at 13C NT (Table 1). 'Tampico' stems were longer at $26 \mathrm{C}$ RZT than at $10 \mathrm{C}$, at both NTs (Table 1). 'Tampico' stems grown at 26C RZT and 20C NT were longer than any other treatment combination (Table 1). Dry weight of 'Tampico' was higher than that of 'Rainier White' (Table 1). Yellow-flowered cultivars, such as 'Tampico', are typically more vigorous than white cultivars (K.C. Sanderson, personal communication). Dry weight of 'Tampico' at 20C NT was lower than at $13 \mathrm{C}$, in contrast, dry weight of 'Rainier White' was not affected by NT (Table 1). Dry weight of either cultivar was not affected by RZT.

'Rainier White' and 'Tampico' plants grown at 26C RZT required less time to flower 
than those at 10C RZT (Table 1). According to Ball (1991), intermediate response cultivars (Group II and III) require 130 days from sowing to flower under southern greenhouse conditions. However, 'Rainier White', a Group II cultivar, required only 66 days from transplanting or 87 days from sowing to flower at $13 \mathrm{C} \mathrm{NT}$ and 10C RZT. Our results agree with those of Sanderson and Martin (1984), who reported that Group II cultivars grown in Auburn, Ala., required an average 69 days from benching to harvest. Night-break lighting of winter-grown snapdragons results in earlier flowering (Erwin, 1991; Sanderson and fink, 1967).

'Tampico' plants grown at $13 \mathrm{C}$ NT and 10C RZT required the longest time to flower. Time to flower was shorter at 26C RZT than at $10 \mathrm{C}$ for 'Rainier White' and 'Tampico' at 13C NT, but both still required more time than plants grown at 20C NT and 10C RZT (Table 1). 'Rainier White' grown at 20C NT and 26C RZT required the shortest time to flower (Table 1). Slight decreases, 1 to 4 days, in cropping times for Group I and II snapdragons in response to increased RZT were reported by Seeley (1965). Earlier flowering has been previously associated with higher night temperatures (Miller, 1960), but root-zone heating alone speeded maturation of other flowers (Barnett et al., 1978; Janes and McAvoy, 1982; Vogelezang, 1988; White and Biernbaum, 1984).

Maintaining the night temperature at 20C had a greater impact on cropping time than root-zone heat. However, plants grown with root-zone heat at the lower night temperature $(13 \mathrm{C})$ produced stems similar in length to those grown without root-zone heat at the higher night temperature. Seeley (1965) demonstrated little significant effect of rootzone heat on snapdragons, but this study demonstrated that the effects of cooler greenhouse conditions may be offset by rootzone heat.

\section{Literature Cited}

Ball, V. 1991. Ball redbook: Greenhouse growing. 15th ed. Geo. J. Ball Publishing, West Chicago, Ill.

Barnett, E.R., D.P. Ormond, and R. Jung. 1978. Soil heating effects on bench-grown chrysanthemums. HortScience 13:591-592.

Erwin, J. 1991. The interaction between light intensity and photoperiod on cut snapdragon flower initiation. Minn. Flower Grower's Assn. Bul. 40(2):1-5.

Hoagland, D.R. and I. Arnon. 1950. The waterculture method for growing plants without soil. Calif. Agr. Expt. Sta. Circ. 347.

Janes, H.W. and R. McAvoy. 1982. Effect of root-zone heating on growth of poinsettias. J. Amer. Soc. Hort. Sci. 107:525-530.

Larsen. A.L. 1965. Use of thermogradient plate for studying temperature effects on seed-germination. Proc. Intl. Seed Test Assn. 30:861867.

Miller, R.O. 1960. Growth and flowering of snapdragons as affected by night temperatures adjusted in relation to light intensity. Proc. Amer. Soc. Hort. Sci. 75:761-768.

Roberts. W.J.. J.W. Bartok. Jr.. E.E. Fabian. and J. Simpkins. 1985. Energy conservation for commercial greenhouses. Northeast Reg. Agr.
Eng. Serv., Ithaca, N.Y. NRAES-3.

Rogers, M.N. 1992. Snapdragons, p. 94-112. In: R.A. Larson (ed.). Introduction to floriculture. 2nd ed. Academic, New York.

Sanderson, K.C. and C.B. Link. 1967. The influence of temperature and photoperiod on the growth and quality of a winter and summer cultivar of snapdragon, Antirrhinum majus L. Proc. Amer. Soc. Hort. Sci. 91:598-611.

Sanderson, K.C. and W.C. Martin. 1984. Evaluation and scheduling of snapdragon cultivars. Alabama Agr. Expt. Sta. Bul. 468. (revised)

Seeley, J.G. 1965. Soil temperature and the growth of greenhouse snapdragons. Proc. Amer. Soc. Hort. Sci. 86:693-694.
Shedlosky, M.E. and J.W. White. 1987. Growth of bedding plants in response to root-zone heating and night temperature regimes. J. Amer. Soc. Hort. Sci. 112:290-295.

Vogelezang, J.V.M. 1988. Effect of root-zone heating on growth, flowering and keeping quality of Saintpaulia. Scientia Hort. 34:101-113.

Wai, K.S. 1990. Growth, flowering and water relations of snapdragons subjected to low night air temperature and elevated root-zone temperature. MS Thesis, Mississippi State Univ., Starkville.

White, J.W. and J.A. Biernbaum. 1984. Effects of root-zone heating on growth and flowering of calceolaria. HortScience 19:289-290. 